\title{
Desplazamiento de trabajadores asalariados en el marco de la libre prestación de servicios en la Unión Europea*
}

Posting of workers in the framework of the free provision of services in the European Union

\section{Óscar Contreras Hernández***}

\section{RESUMEN}

El presente artículo examina la libre prestación de servicios en la Unión Europea; esta libertad económica otorga el derecho a las empresas a trasladarse de un Estado miembro a otro para dar respuesta a una demanda de servicios transnacional y, al mismo tiempo, es el fundamento juridico del desplazamiento de trabajadores cuando las empresas desplazadas deciden llevar consigo a sus empleados. Ahora bien, aun siendo una evidencia positiva del proceso de integración económica en la Unión Europea (UE), esta libertad económica es susceptible de provocar situaciones de competencia desleal entre empresas y/o situaciones de discriminación entre trabajadores locales y desplazados, fundamentalmente por las divergencias que, en términos sociojurídicos y económicos, existen en el territorio de la UE.

PALABRAS CLAVE: Globalización, libre comercio, Espacio Económico Europeo, derecho de la Unión Europea, prestación de servicios transnacional, desplazamiento de trabajadores.

\begin{abstract}
This article examines the free provision of services in the European Union, which entitles companies to move from one member State to another, to carry out transnational services. At the same time, it is the legal basis of posting of workers when the companies that have moved decide to take their employees. Now then, despite of a positive evidence of the economic integration process in the European Union, this economic freedom sometimes causes unfair competition among companies as well as situations of discrimination between local and posted workers; basically, due to disagreements in legal, economical and social issues in the territory of the European Union.
\end{abstract}

KEY WORDS: Globalization, free trade, European Economic Area, European Union Law, transnational provision of services, posting of workers.

\footnotetext{
* Recibido: 4 de febrero de 2013. Aceptado: $1^{\circ}$ de abril de 2013.

** Profesor-investigador asociado del Departamento de Derecho del Trabajo y de la Seguridad Social de la Universidad de Castilla-La Mancha, España (oscar.contreras@alu.ucm.es).
} 


\section{Sumario}

1. Introducción

2. Delimitación del fenómeno

A) Las libertades económicas de las empresas en la UE y los sistemas de relaciones laborales

B) El desplazamiento de trabajadores asalariados como expresión de la movilidad laboral geográfica de carácter internacional

c) Desplazamientos de trabajadores en el Espacio Económico Europeo (EEE)

3. Aproximación jurídica. Marco legal aplicable

A) Antecedentes jurídicos del desplazamiento de trabajadores en la UE

B) La trasposición de la Directiva 96/71/CE y equilibrio normativo entre libre prestación de servicios y derechos laborales

4. Consideraciones finales

\section{Introducción}

En un escenario de creciente integración económica internacional, de reducción progresiva de los obstáculos al libre comercio y de una omnipresente globalización económica, cada vez un mayor número de empresas presta sus servicios en países distintos a los de su constitución. A menudo, este suceso implica la movilidad de los factores de producción, de forma que, en ocasiones, el factor trabajo es desplazado desde el país de origen al país de destino. Inexorablemente este fenómeno afecta a los sistemas de relaciones laborales, pues a medida que se incrementan las relaciones comerciales entre paises, los mismos deben responder a las demandas crecientes de flexibilidad, productividad y competitividad que son exigidas a las empresas, así como a los Estados.

Estas circunstancias han modificado el sentido original de los movimientos internacionales de trabajadores, vinculados tradicionalmente al fenómeno migratorio, dando lugar a la creación de una nueva expresión de movilidad laboral geográfica de la mano de obra: el desplazamiento temporal de trabajadores asalariados de carácter internacional por orden o iniciativa empresarial.

En el ámbito geográfico internacional, este fenómeno se encuentra regulado según lo dispuesto en normas de derecho internacional privado. En consecuencia, las vicisitudes propias de la relación laboral vienen configuradas atendiendo a varios ordenamientos jurídicos nacionales, así como a diversos sistemas jurisdiccionales, circunstancia que provoca conflictos respecto de la ley aplicable al contrato de trabajo del trabajador desplazado. 
En el ámbito de la Unión Europea, esta manifestación de la movilidad geográfica laboral tiene su base jurídica en una de las libertades económicas del denominado "mercado interior": la libre prestación de servicios transnacional. Ciertamente, sin la posibilidad de desplazar trabajadores, la mayoría de las empresas que deciden ofrecer servicios más allá de sus fronteras nacionales, no tendrían esa posibilidad. Sin embargo, este fenómeno plantea complejas cuestiones jurídicas, sociales y económicas que fueron objeto de regulación jurídica en Europa a través de la aprobación de la Directiva 96/71/CE del Parlamento Europeo y del Consejo del 16 de diciembre de 1996, "sobre el desplazamiento de trabajadores efectuado en la Unión Europea en el marco de una prestación de servicios transnacional”. Como expresan sus considerandos, la finalidad principal de esta norma comunitaria es impedir la competencia desleal entre empresas, así como el posible deterioro de los derechos de los trabajadores desplazados.

No obstante, esta norma parece no haber resuelto los principales inconvenientes que motivaron su aprobación en 1996. En la actualidad existe un intenso debate en el ámbito académico, social, empresarial e institucional conectado con este fenómeno, sobre todo a raíz de los pronunciamientos recientes del máximo órgano jurisdiccional a nivel Europeo, es decir, el Tribunal de Justicia de la Unión Europea (TJUE), el cual ha modificado tangencialmente la exégesis de esta norma comunitaria. En síntesis, este Tribunal ha interpretado la licitud de la obtención de una ventaja competitiva basada en la falta de armonización legislativa sobre algunos derechos laborales, así como la ponderación entre derechos y libertades fundamentales en la Unión Europea.

El presente artículo analiza el desplazamiento de trabajadores asalariados en la UE relacionado con las prestaciones de servicios trasnacionales, examinando los aspectos normativos y de regulación comunitaria que le son inherentes. El objetivo general es observar hasta qué punto se ha dado una respuesta adecuada a las exigencias socioeconómicas conectadas con el fenómeno, es decir, la garantía de la libre prestación de servicios trasnacionales en el territorio de la Unión Europea, la competencia leal entre empresas y la protección adecuada de los trabajadores desplazados.

\section{Delimitación del fenómeno}
A) Las libertades económicas de las empresas en la UE y los sistemas de relaciones laborales

Ineludiblemente, hablar del contexto económico actual obliga a hacer referencia al fenómeno de la "globalización". Aunque no se va a profundizar al respecto, 
resulta recomendable llevar a cabo una aproximación a la misma, pues tangencialmente está conectada con el objeto de estudio del presente artículo.

Como señala Guillermo de la DEHESA, "la globalización se puede definir como un proceso dinámico de creciente libertad e integración mundial de los mercados de trabajo, bienes, servicios, tecnología y capitales". ${ }^{1}$ La misma puede identificarse, además, como un proceso creciente de interdependencia entre países, sociedades, instituciones y empresas que sienta sus fundamentos sobre todo en un proceso de integración económica de carácter supranacional.

Gráfica 1. Volumen del COMERCiO MUNDial DE MERCANCías, POR GRANDES GRUPOS DE PRODUCTOS, 1950-2012

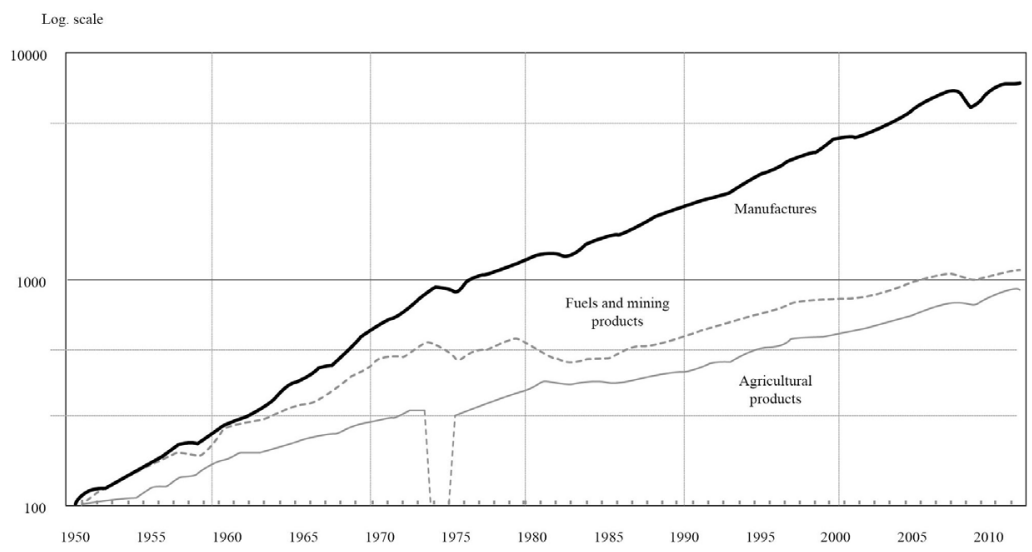

Fuente: Organización Mundial del Comercio (омc). "Estadísticas del comercio internacional” 2013 (gráfica 3), disponible en: http://www.wto.org/spanish/res_s/statis_s/its2013_s/its13_charts_s. htm.

Así, la globalización económica ha sido impulsada, entre otros motivos, por la reducción progresiva de los obstáculos al "libre comercio" internacional a través de la aprobación de diversos acuerdos y tratados de integración económica, ${ }^{2}$ junto con la constitución de organismos y áreas de unión económica internacional, tales como la Organización Mundial del Comercio (омc) y la Unión Europea,

\footnotetext{
1 DehesA, Guillermo de LA. Comprender la globalización, prólogo de Paul Krugman, 3a. ed., Alianza Editorial, Madrid, 2007, p. 19.

2 Entre otros, Acuerdo General sobre Aranceles Aduaneros y Comercio de 1947 (GaT); Asociación Europea de Libre Comercio de 1960 (AELC, EFTA en inglés); Comunidad Económica de África Occidental de 1975 (CEAO); Mercado Común del Sur de 1991 (Mercosur); Tratado Norteamericano de Libre Comercio de 1992 (NAFA); Acuerdos Multilaterales sobre el Comercio de Mercancías de 1994; Acuerdo General sobre el Comercio de Servicios de 1994 (Agcs).
} 
respectivamente. En suma, han supuesto un factor estimulante del comercio mundial de mercancías, sobre todo a partir de la segunda mitad del siglo xx. Una de las consecuencias directas de este fenómeno es que tanto los bienes como los servicios y, en definitiva, el capital se mueven con casi total libertad entre los distintos países de todo el mundo.

Desde una perspectiva económico-empresarial, la globalización incide directamente en la creación de grupos multinacionales como respuesta al nuevo “mercado global". Pero no sólo implica, entre otras respuestas organizativas, el traslado de las empresas o partes de su producción a otros países (deslocalización), la expansión geográfica o la "internacionalización” de las compañías, la integración o fragmentación de la actividad productiva, la subcontratación, outsourcing internacional o el traslado temporal a otros paises para efectuar prestaciones de servicios transnacionales. ${ }^{3}$

Considerando esta circunstancia, el crecimiento continuado del volumen mundial de intercambio de mercancías desde 1950, así como la capacidad de los factores productivos para trasladarse de un mercado a otro, conviene señalar que en las dos últimas décadas la movilidad geográfica del factor trabajo ha tenido una significación relativa dentro del proceso de integración económica internacional. Esta afirmación se explica de la siguiente forma: el intercambio de bienes, servicios y sobre todo de capitales no se mueve a la misma velocidad que otros factores de producción, como el trabajo. Aunque con obviedad, resulta interesante señalarlo, pues el fenómeno de la "globalización”, como apunta BEck, "de la economía, de los mercados, de la competencia por un puesto de trabajo, de la producción, de la prestación de servicios, de la información y de la vida en general", ${ }_{4}^{4}$ es, ante todo, económica.

Ahora bien, aunque fundamentalmente económica, la globalización ha incidido de forma directa sobre el aumento exponencial de los movimientos transnacionales de la fuerza de trabajo e inexorablemente sobre los sistemas de relaciones laborales. Esto es debido, sobre todo, al fenómeno migratorio, pero no únicamente. Las respuestas organizativo-empresariales desplegadas por las compañías para responder a la nueva estructura o economía global pueden implicar el traslado definitivo de la empresa, la apertura de un establecimiento filial en el extranjero o el desplazamiento temporal para la prestación de un servicio en otro Estado, y con ello un eventual traslado o desplazamiento de trabajadores propios como alternativa a la contratación de trabajadores locales. Circunstancia que, en

\footnotetext{
${ }^{3}$ Véase al respecto el capítulo x, "Los mercados de trabajo en un contexto de globalización", en Palacio Morena, Juan Ignacio y Álvarez Aledo, Carlos. El mercado de trabajo: análisis y políticas, Akal, Madrid, 2004, pp. 298 y sS.

${ }^{4}$ Beck, UlRich. ¿Qué es la globalización? Falacias del globalismo, respuestas a la globalización, traducción de Bernardo Moreno y María Rosa Borrás, Paidós, Barcelona, 2008, p. 15.
} 
cualquier caso, queda legitimada por los procesos de “integración económica”, la libertad empresarial, así como en virtud del denominado "derecho económico internacional". ${ }^{5}$ El mismo, junto con los tratados de libre comercio y la reducción de los obstáculos al comercio internacional, permite ampliar el ámbito geográfico de actuación de las empresas más allá de las fronteras nacionales.

Así sucede en Europa, según lo dispuesto en los Tratados Fundacionales y en el Tratado de Funcionamiento de la Unión Europea (TFUE) en lo relativo al "mercado interior europeo". Éste es uno de los mecanismos de integración económica en la Unión Europea basado en el establecimiento de un mercado común entre todos los países miembros, en el que circulan libremente mercancías, personas, servicios y capitales, y donde los ciudadanos de la Unión pueden vivir, trabajar, estudiar o hacer negocios con libertad. ${ }^{6}$ Dentro de esta última afirmación, la "libertad de establecimiento" y la "libre prestación de servicios" desempeñan actualmente un papel fundamental como instrumentos clave para el desarrollo económico de la Unión.

Ambas libertades económicas son dos de los pilares sobre los que se asienta el mercado interior europeo e, inequívocamente, afectan de forma decisiva al proyecto de efectiva integración europea, al crecimiento económico y a la competitividad global del proyecto común, pues, como expresa Fernández-Costales, permiten al empresario "desarrollar actividades productivas sin cortapisas, sin barreras al comercio y a la movilidad de los factores de producción”. De este modo, en la Unión Europea estas libertades otorgan a los empleadores el derecho a efectuar traslados definitivos o desplazamientos temporales de un Estado miembro a otro, y con ello eventualmente la movilidad geográfica intracomunitaria de los trabajadores asalariados.

Aunque sobre ambas libertades se apoya el mercado interior, únicamente se va a observar aquella libertad económica a través de la cual se canaliza el fenómeno del desplazamiento temporal de trabajadores en el marco de una prestación de servicios transnacional en la Unión Europea: la "libre prestación de servicios".

La "libertad de prestación de servicios" de las personas jurídicas en la Unión Europea, contenida en el capítulo 3, artículos 56-62, del Tratado de Funciona-

\footnotetext{
5 Sobre el mismo, véase Herdegen, Matrias, Derecho económico internacional, traducción de Laura García Gutiérrez y Katia Fach Gómez, Thomson-Civitas, Madrid, 2005. Asimismo, resulta de especial interés el artículo de Fernández RozAS, José CARlos. "El derecho económico internacional de la globalización", en Guerra y paz (1945-2009). Obra homenaje al Dr. Torres Fernández, Universidad del País Vasco, Bilbao, 2010, pp. 197-236.

${ }^{6}$ Véase Comisión EURopeA. "Mercado Interior"; http://europa.eu/legislation_summaries/internal_market/index_es.htm, así como el artículo 26 del título I de la versión consolidada del Tratado de Funcionamiento de la Unión Europea.

7 Fernández-Costales MuñIz, Javier. "La determinación de la normativa aplicable en el proceso social español en los litigios surgidos en el marco de los desplazamientos trasnacionales de trabajadores. Alegación y prueba del derecho extranjero", en Revista Jurídica de Castilla y León, No. 10, 2006, pp. 207-274.
} 
miento de la UE, conlleva la realización de una actividad económica con carácter temporal en un Estado miembro distinto al lugar de constitución donde se encuentra establecida. La finalidad de la misma es otorgar el derecho a las personas físicas y jurídicas a prestar sus servicios profesionales, empresariales o artísticos, de forma temporal en cualquier país de la Unión sin necesidad de establecerse en el mismo, es decir, con ausencia de participación estable y continua en la vida económica del Estado miembro anfitrión y en igualdad de condiciones con los nacionales del Estado en el cual se presta el servicio.

En este sentido, las empresas que deciden llevar a cabo una actividad económica transitoria fuera de las fronteras nacionales lo hacen en virtud de la libre prestación de servicios. Este derecho además es el fundamento jurídico del desplazamiento temporal de trabajadores cuando, eventualmente, las empresas desplazadas deciden llevar consigo a sus empleados para efectuar la prestación de servicios transnacional. Ahora bien, esta circunstancia, tal como se ha venido observando desde numerosas instituciones sociales, académicas y gubernamentales, podría "dar lugar a situaciones de discriminación entre trabajadores de un Estado miembro y trabajadores desplazados, así como a situaciones de competencia desleal entre empresas que actúan en el mercado interior". ${ }^{8}$

Uno de los elementos que configuran tangencialmente la movilidad laboral geográfica de carácter internacional es el coste que el factor trabajo presenta entre países. En la actualidad, los costes laborales en los mercados de trabajo nacionales en la Unión Europea no están armonizados. La observación de algunos indicadores relacionados con el objeto de estudio, como son los costes laborales medios por hora trabajada y la cuantía de los salarios mínimos por países, muestran las diferencias en el nivel de costes laborales que el factor trabajo presenta actualmente entre gran parte de los Estados miembros.

Asimismo, una observación de la existencia y la cuantía del "salario mínimo" establecido en los paises miembros resulta apropiada para analizar las posibles consecuencias sobre la competencia empresarial entre operadores económicos y sobre los derechos sociosalariales afectados, pues, como veremos, durante el desplazamiento de trabajadores asalariados en la Unión Europea efectuado por las empresas, el salario mínimo es una de las condiciones de empleo sobre las que existe una protección jurídica especial. Sin embargo, debido a las divergencias existentes entre los ordenamientos nacionales al respecto, en ocasiones, estas limitaciones resultan insuficientes en determinados supuestos de desplazamiento.

8 Ibidem, p. 22. 
Gráfica 2. Costes laborales medios (tOTAles) POR hORA tRabajAdA, UE-28.

TRABAJADORES MANUALES Y NO MANUALES EMPLEADOS A TIEMPO COMPLETO

EN EL SECTOR PRIVADO (2013) ${ }^{9}$

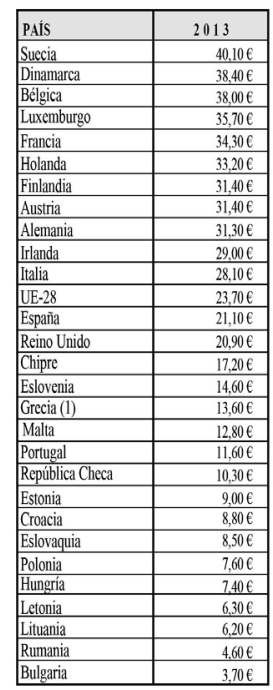

(1) Datos basados en estimaciones

de Eurostat para el 3er. y 40. trimestre

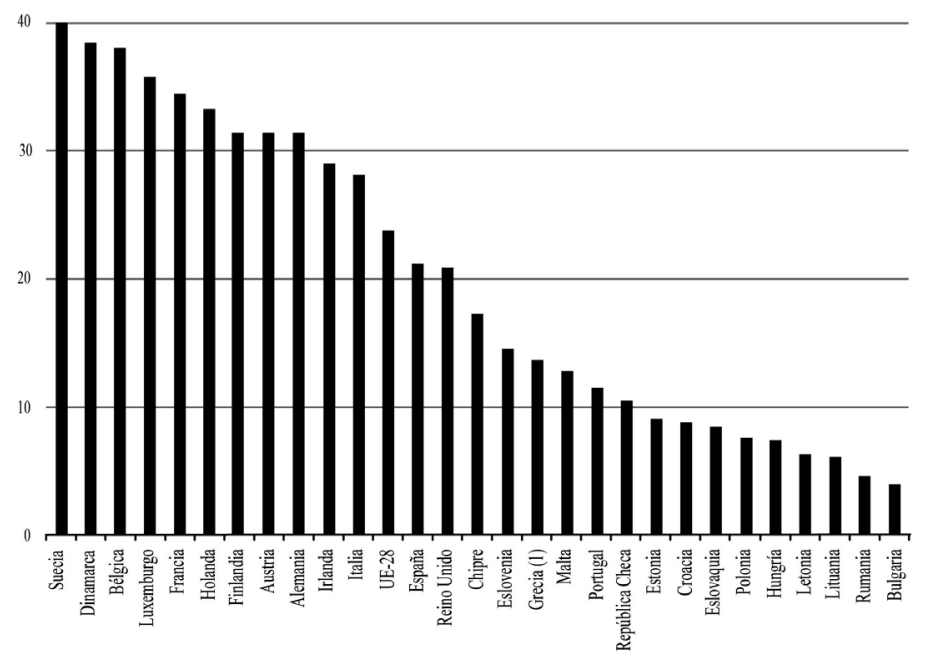

FUENTE: Eurostat y elaboración propia.

En la Unión Europea, sólo veintiuno de los veintiocho Estados miembros (Bélgica, Bulgaria, Croacia, Eslovenia, Eslovaquia, España, Estonia, Francia, Grecia, Holanda, Hungría, Irlanda, Letonia, Lituania, Luxemburgo, Malta, Polonia, Portugal, República Checa, Reino Unido y Rumanía) tienen establecida, en sus respectivas leyes nacionales o acuerdos intersectoriales de ámbito nacional, la cuantía del "salario mínimo" a percibir por los trabajadores asalariados a tiempo completo.

Tal como sucedía en la comparativa del nivel de costes laborales por países, la gráfica 3 muestra la existencia de notables diferencias en las cuantías del salario mínimo establecido en los Estados miembros de la Unión Europea. Estas diferencias, al menos en cierto grado, coinciden o son similares a las diferencias existentes entre los Estados miembros considerando el PIB per capita, no obstan-

\footnotetext{
${ }_{9}$ Incluye a todas las empresas con diez o más empleados de todos los sectores de la economía excepto el sector público. Véase http://appsso.eurostat.ec.europa.eu/nui/show.do?dataset=lc_lci_levEtlang=en.
} 
te, ante todo, vienen a mostrar las considerables disparidades cuantitativas en costes sociolaborales que el factor trabajo presenta en la Unión Europea.

Gráfica 3. Salarios mínimos mensuales en los países de la Unión Europea (2013) ${ }^{10}$

\begin{tabular}{|l|c|}
\hline PAí' ${ }^{\prime}$ & 2013 \\
\hline Luxemburg 0 & $1.874,19 €$ \\
\hline Bélgica & $1.501,82 €$ \\
\hline Holanda & $1.469,40 €$ \\
\hline Irlanda & $1.461,85 €$ \\
\hline Francia & $1.430,22 €$ \\
\hline Reino Unido & $1.264,25 €$ \\
\hline Eslovenia & $783,66 €$ \\
\hline España & $752,85 €$ \\
\hline Malta & $697,42 €$ \\
\hline Grecia & $683,76 €$ \\
\hline Portugal & $565,83 €$ \\
\hline Polonia & $392,73 €$ \\
\hline Croacia & $372,35 €$ \\
\hline Hungria & $340,55 €$ \\
\hline Eslovaquia & $337,70 €$ \\
\hline Estonia & $320,00 €$ \\
\hline República Checa & $312,01 €$ \\
\hline Lituania & $289,62 €$ \\
\hline Letonia & $286,66 €$ \\
\hline Bulgaria & $158,50 €$ \\
\hline Rumania & $157,50 €$ \\
\hline
\end{tabular}

${ }^{1}$ Los Estados miembros no mostrados no tienen establecido salario minimo

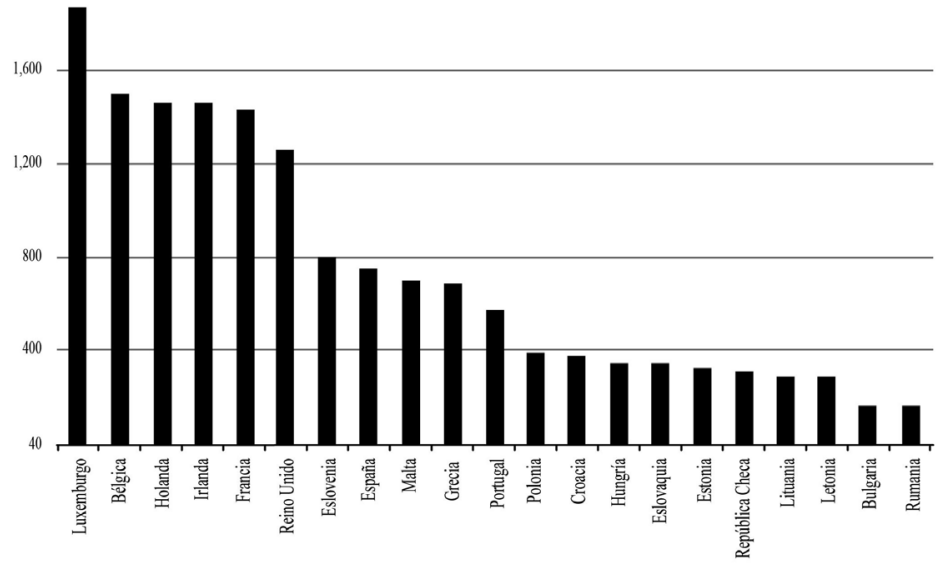

FUENTE: Eurostat y elaboración propia.

B) El desplazamiento de trabajadores asalariados como expresión de la movilidad laboral geográfica de carácter internacional

Tradicionalmente, la "movilidad geográfica internacional" de trabajadores se ha contemplado como un suceso vinculado al fenómeno migratorio por el que los ciudadanos residentes de un país se trasladan a otro con la finalidad de incrementar sus oportunidades de empleo en un mercado de trabajo distinto al de su origen o residencia. ${ }^{11}$ El Convenio No. 97 de la Organización Internacional del Trabajo (огт) de 1949, relativo a los trabajadores migrantes, así lo expresa en su

\footnotetext{
${ }^{10}$ La cuantía de salarios mínimos mostrada es bruta, esto es, antes de las correspondientes deducciones por impuestos y contribuciones sociales. En algunos paises el importe del salario mínimo es fijado por hora o semana (Francia y Reino Unido, por ejemplo). En estos casos los importes mensuales han sido calculados teniendo en cuenta los factores de conversión por paises. Lo mismo sucede en los casos donde el salario mínimo es pagado en 14 pagas (España, Grecia y Portugal). El mismo se ha ajustado y convertido a 12 pagas. Véase http://epp.eurostat.ec.europa. eu/tgm/web/table/description.jsp.

${ }^{11}$ Entre otros, así lo expresan Campbel. R. Mc Connell et al. Economía laboral, 7a. ed., McGraw-Hill, Madrid, 2007, pp. 270 y ss.; Borjas, George J. Labor Economics, 5a. ed., McGraw-Hill-Irvin, Boston, 2009, p. 317.
} 
artículo 11.1, al definir como "trabajador migrante" a toda persona "que emigra de un país a otro para ocupar un empleo".12

En la Unión Europea, esta variante tradicional de movilidad laboral internacional, basada en el movimiento migratorio de trabajadores entre Estados miembros, tiene su base jurídica en la denominada "libre circulación de los trabajadores". Este derecho implica que los ciudadanos europeos puedan desplazarse, trasladarse y/o residir en cualquiera de los países de la Unión Europea con objeto de ejercer en él un empleo, así como para responder a ofertas efectivas de trabajo. ${ }^{13}$

Esta expresión de movilidad laboral geográfica puede ser identificada como un supuesto de "movilidad por el empleo", en la que el traslado del trabajador obedece a la búsqueda de un empleo fuera de las fronteras nacionales o es la respuesta a una oferta previa para ocupar un puesto de trabajo en un mercado laboral distinto al de procedencia. ${ }^{14}$

Ahora bien, no es ésta la única forma que actualmente adopta el proceso de movilidad laboral geográfica. Tanto en el escenario internacional como europeo existe otra manifestación que, conectada con la globalización económica, la revolución tecnológica, el mayor grado de integración económica a nivel mundial y los procesos de descentralización productiva empresarial, ha protagonizado las dos últimas décadas: la movilidad o desplazamiento temporal de trabajadores asalariados efectuado por las empresas para dar respuesta a una demanda internacional de servicios a corto plazo.

El Convenio 143 de la Organización Internacional del Trabajo "sobre los trabajadores migrantes" ya reconocía en 1975 la existencia de esta nueva expresión de movilidad geográfica internacional de trabajadores. Sin embargo, no lo hacía de forma inclusiva dentro del espectro de "trabajadores migrantes". El Convenio, de forma expresa, excluye de su ámbito de aplicación a:

[...] las personas empleadas en organizaciones o empresas que operan dentro del territorio de un país que han sido admitidas temporalmente en dicho país, a solicitud de sus empleadores, para cumplir trabajos o funciones específicas por un periodo definido o limitado de tiempo y que están obligadas a abandonar el país al término de sus trabajos o funciones. ${ }^{15}$

\footnotetext{
${ }_{12}$ Cfr. Convenio No. 97 de la orr. Disponible en: http://www.lo.org/ilolex/cgi-lex/convds.pl?C097.

${ }_{13}$ Cfr. Artículo 45 de la versión consolidada del Tratado de Funcionamiento de la ue del 30 de marzo de 2010.

14 En este sentido, CASAS BAAmonde, MARiA EmiliA. "Desplazamientos temporales de trabajadores e interpretación judicial del Convenio de Roma", Relaciones laborales, No. 1, 1994, pp. 4 y 5; Rodriguez Piñero, Manuel. "El desplazamiento temporal de trabajadores y la Directiva 96/71/CE", en Relaciones Laborales, No. 23, 1999, pp. 78 y 79; ESTEBAN DE LA Rosa, Gloria y Molina Navarrete, Cristóbal. La movilidad transnacional de trabajadores; reglas y prácticas, Comares, Granada, 2002, p. 2.

${ }^{15}$ Cfr. Artículo 11.2.e) del Convenio No. 143 de la olт. Disponible en: http://www.lo.org/ilolex/cgi-lex/convds.pl?C143.
} 
Desde esa óptica, la distinción entre "trabajador migrante y trabajador desplazado" se encuentra en que el primero basa su movilidad en una decisión propia, y aunque puede no ser así, la duración del traslado suele ser permanente. El segundo no se desplaza geográficamente por iniciativa propia, sino que es desplazado siguiendo una orden o iniciativa empresarial, y el carácter del desplazamiento es siempre temporal.

Según el marco conceptual desarrollado por GREEN para examinar la movilidad geográfica laboral, los diferentes tipos de movilidad se pueden clasificar en función de la frecuencia y la duración del traslado o movimiento. ${ }^{16}$ De este modo, los mismos se pueden extender desde el movimiento diario que se produce entre el lugar de residencia de un trabajador y su lugar de trabajo, hasta el traslado permanente o migración, pasando por aquellos desplazamientos que suponen la necesidad de pernoctar en un lugar distinto al de origen pero sin reubicación o cambio de residencia. Como afirma GreEn, la movilidad a corto plazo, "por el empleo", suele tener una duración de entre tres y doce meses, en función de las definiciones desarrolladas por Naciones Unidas para delimitar el concepto de migrante a largo plazo y migrante a corto plazo. Por su parte, una “asignación laboral" a corto plazo puede identificarse con un tipo particular de movilidad laboral geográfica que no implica una reubicación del trabajador o cambio de residencia habitual. Siguiendo esta consideración, el envío de trabajadores asalariados o desplazamiento temporal de trabajadores, como un tipo de movilidad laboral geográfica a corto plazo, puede incluirse dentro de las denominadas "asignaciones laborales de carácter internacional” a corto plazo.

Acotado al ámbito territorial de la Unión Europea, esta expresión de movilidad geográfica internacional de trabajadores, donde una persona jurídica desplaza temporalmente mano de obra a otro Estado para dar cumplimiento a un contrato entre empresas, es una manifestación de las libertades económicas en la Unión Europea; concretamente de la "libre prestación de servicios" reconocida a las personas jurídicas establecidas en un Estado miembro. A partir de esa realidad, la pregunta que inmediatamente surge es ¿pero qué se entiende actualmente por "prestación de servicios transnacional"? Para responder a esta pregunta resulta apropiado observar, en primer lugar, el "Acuerdo General sobre el Comercio de Servicios", ${ }^{17}$ que en su artículo 1.3.b define qué se entiende por

\footnotetext{
${ }^{16}$ Cfr. Green, Anne et al. Short-Term Mobility, Institute for Employment Research, University of Warwick, Coventry, 2009, p. 9.

${ }^{17}$ El Acuerdo General sobre el Comercio de Servicios (AGCS, GATS en inglés) es el primer conjunto de principios y normas convenidos de forma multilateral para regir el comercio internacional de servicios. La creación del AGcs fue uno de los logros principales de la Ronda Uruguay cuyos resultados entraron en vigor en enero de 1995.
} 
servicios: "el término servicios comprende todo servicio de cualquier sector, excepto los servicios suministrados en ejercicio de facultades gubernamentales". Conviene señalar que dentro de los cuatro modos de prestación de servicios que presenta este acuerdo se incluye el suministro de un servicio por personas de un Estado miembro en el territorio de otro Estado miembro para efectuar actividades de todo tipo: construcción, asesoramiento, distribución, turismo, instalación de maquinaria, etcétera. De este modo, según el acuerdo recién citado, el término "servicios" no obedece de forma estricta a la clasificación clásica de las actividades económicas por sectores productivos: primario, secundario y terciario; actualmente se entiende por "servicios" la prestación de cualquier servicio efectuado entre empresas, con independencia del "sector económico o de actividad" al que pertenezcan.

En segundo lugar, debemos observar lo dispuesto en el artículo 57 del Tratado de Funcionamiento de la Unión Europea, que dice lo siguiente:

Con arreglo a los Tratados, se considerarán como servicios las prestaciones realizadas normalmente a cambio de una remuneración, en la medida en que no se rijan por las disposiciones relativas a la libre circulación de mercancías, capitales y personas. Los servicios comprenderán, en particular:

Actividades de carácter industrial;

Actividades de carácter mercantil;

Actividades artesanales;

Actividades propias de las profesiones liberales.

Estos preceptos legales parecen corroborar una evidencia: hoy en día toda actividad económica entre sujetos económicos donde se intercambia una prestación a cambio de remuneración puede ser considerada como una prestación de servicios. En palabras de APARICIO, "un servicio es todo aquello que puede ser objeto de comercio; y puede ser objeto de comercio cualquier actividad económica sobre la que no exista una prohibición expresa". ${ }^{18}$

Atendiendo a los supuestos mencionados, en ellos se puede identificar una “descentralización productiva transnacional”, basada en una subcontratación empresarial vinculada a un contrato entre empresas que, con independencia del sector o la actividad económica contratada o subcontratada entre ellas, es considerada como una prestación de servicios.

\footnotetext{
${ }_{18}$ Aparicio Tovar, Joaquin. "Desplazamiento de trabajadores y prestaciones de servicios", en I Seminario de Derecho del Trabajo y Crisis Global, ponencia presentada en el máster en empleo, RRLL y diálogo social en Europa, UCLM, Albacete, marzo de 2011.
} 


\section{C) Desplazamientos de trabajadores en el Espacio Económico Europeo (EEE) $)^{19}$}

En la actualidad, aproximadamente un millón de trabajadores asalariados son desplazados cada año por parte de sus empleadores dentro del territorio del Espacio Económico Europeo..$^{20}$ Ciertamente, el análisis cuantitativo del fenómeno ofrece una panorámica de la magnitud de este tipo de movilidad laboral geográfica de carácter internacional, la cual es fruto de la integración económica experimentada en Europa durante la segunda mitad del siglo xx.

Gráfica 4. Desplazamientos de trabajadores en el eee. Por país de origen (2011)

\begin{tabular}{|l|r|}
\hline PAis & \multicolumn{1}{|c|}{ DESP. } \\
\hline Polonia & 227.930 \\
\hline Alemania & 226.850 \\
\hline Francia & 144.256 \\
\hline Rumania & 59.363 \\
\hline Hungria & 57.848 \\
\hline Bélgica & 55.931 \\
\hline Portugal & 54.043 \\
\hline España & 48.479 \\
\hline Eslovenia & 42.485 \\
\hline Eslovaquia & 40.926 \\
\hline Luxemburgo & 39.385 \\
\hline Italia & 35.611 \\
\hline Reino Unido & 35.368 \\
\hline Austria & 28.806 \\
\hline Holandia & 25.986 \\
\hline República Checa & 16.102 \\
\hline Estonia & 15.322 \\
\hline Suecia & 11.771 \\
\hline Dinamarca & 11.491 \\
\hline Lituania & 9.515 \\
\hline Bulgaria & 7.429 \\
\hline Letonia & 4.287 \\
\hline Irlanda & 3.106 \\
\hline Finlandia & 2.668 \\
\hline Noruega & 2.163 \\
\hline Grecia & 888 \\
\hline Islandia & 377 \\
\hline Malta & 318 \\
\hline Liechtenstein & 63 \\
\hline Chipre & 38 \\
\hline & \\
\hline
\end{tabular}

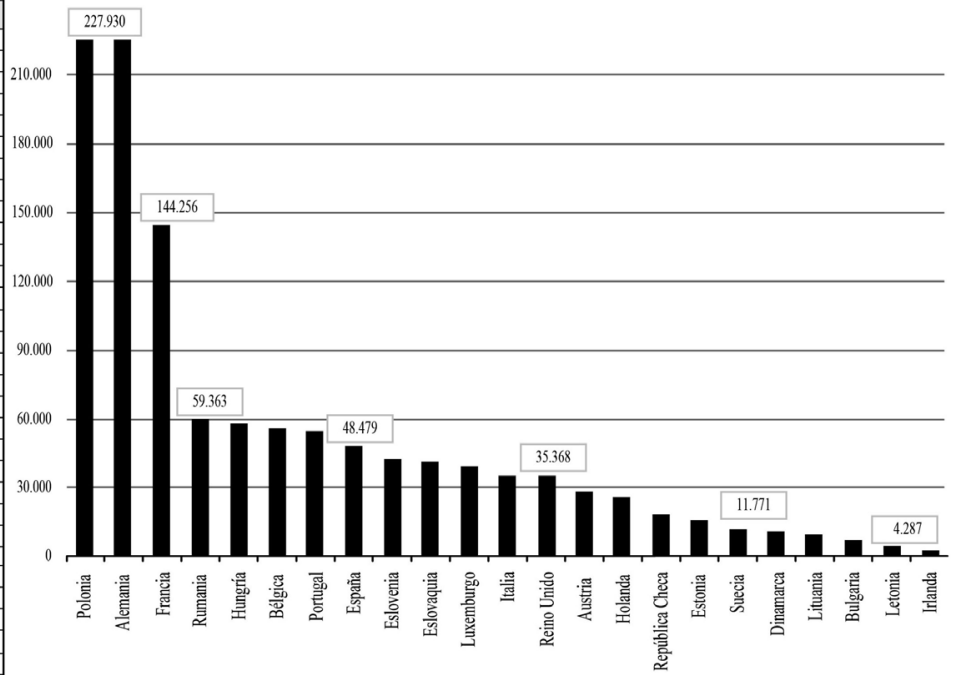

FuENTE: Comisión Europea y elaboración propia.

${ }^{19}$ La información estadistica que se va a transcribir en este epígrafe, recopilada por la Comisión Europea, se refiere al Espacio Económico Europeo (EEE), el cual está formado por la totalidad de los Estados miembros de la Unión Europea y por los paises pertenecientes a la Asociación Europea de Libre Comercio (AELC, EFTA en inglés) a excepción de Suiza. En estos paises, como miembros partícipes en el "mercado interior" de la Unión Europea, es de aplicación lo dispuesto en la regulación europea sobre desplazamiento de trabajadores, asi como lo dispuesto por la normativa de seguridad social en lo referente a las obligaciones administrativas y la cobertura social de estos trabajadores.

${ }^{20}$ Cfr. Comisión EuropeA, "Commission staff working document. Impact assessment. Revision of the legislative framework on the posting of workers in the context of provision of services", swD (2012) 63 final, partie 1, Bruselas, 2012, disponible en: http://ec.europa.eu/social/main.jsp?catld=471, y ComIsIón EUROPEA, "Posting of workers in the European Union and EFTA countries: Report on A1 portable documents issued in 2010 and 2011", Bruselas, 2013. Disponible en: http://europa.eu/rapid/press-release_MEMo-13-1103_en.htm. 
En 2011, último año del que se disponen estadísticas oficiales sobre el fenómeno, un total 1.208.805 desplazamientos temporales se efectuaron en el territorio del Espacio Económico Europeo. Si se observa la gráfica 4 se puede apreciar que Polonia fue el Estado miembro "de origen" en el que mayor número de desplazamientos se llevaron a cabo, concretamente 227.930; Alemania fue el segundo país que contabilizó una cifra más elevada de desplazamientos con origen en su territorio: 226.850; asimismo, Francia, con un total de 144.256 desplazamientos efectuados desde suelo francés, fue el tercer país con mayor número de desplazamientos. Entre los tres vinieron a suponer más de la mitad del total de desplazamientos acontecidos en 2011.

Analizando los datos ofrecidos por la Comisión Europea, se puede observar que más del 60\% del total de los desplazamientos desde la perspectiva de origen proceden de la UE-15; el 38\% de la UE-12, ${ }^{21}$ y poco más del $1 \%$ procede de los países pertenecientes a la EFTA.

Gráfica 5. Desplazamientos de trabajadores en el eEe. Por país de acogida (2011)

\begin{tabular}{|l|c|}
\hline PAiS & DESP. \\
\hline Alemania & 311.361 \\
\hline Francia & 161.954 \\
\hline Bélgica & 125.107 \\
\hline Holanda & 105.885 \\
\hline Austria & 76.335 \\
\hline Italia & 64.223 \\
\hline Suiza & 51.987 \\
\hline España & 47.640 \\
\hline Reino Unido & 37.247 \\
\hline Suecia & 24.412 \\
\hline Luxemburgo & 24.295 \\
\hline Finlandia & 22.183 \\
\hline Noruega & 21.603 \\
\hline República Checa & 17.144 \\
\hline Polonia & 16.013 \\
\hline Portugal & 13.345 \\
\hline Dinamarca & 11.002 \\
\hline Rumania & 10.476 \\
\hline Hungria & 9.924 \\
\hline Grecia & 7.763 \\
\hline Eslovaquia & 6.876 \\
\hline Irlanda & 6.084 \\
\hline Bulgaria & 4.006 \\
\hline Eslovenia & 2.676 \\
\hline Lituania & 2.248 \\
\hline Estonia & 1.904 \\
\hline Letonia & 1.788 \\
\hline Malta & 1.449 \\
\hline Chipre & 1.042 \\
\hline Liechtenstein & 763 \\
\hline Islandia & 559 \\
\hline & \\
\hline
\end{tabular}

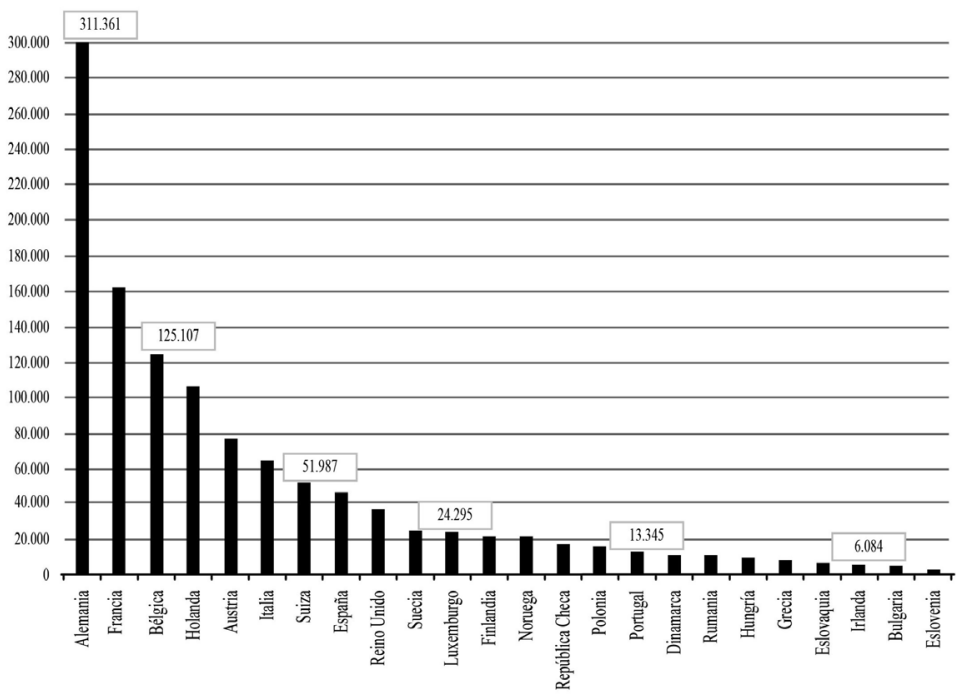

FUENTE: Comisión Europea y elaboración propia.

${ }^{21}$ Con esta nomenclatura el Documento de trabajo de la Comisión Europea que acompaña a los documentos de propuesta de revisión de la Directiva 96/71/CE, se refiere a la UE-15 como aquellos paises que formaban parte de la Unión Europea antes de 2004 (Alemania, Austria, Bélgica, Dinamarca, España, Francia, Finlandia, Grecia, Holanda, Irlanda, Italia, Luxemburgo, Portugal, Reino Unido, Suecia) y a la UE-12 como aquellos paises que hoy conforman la Unión Europea y que fueron incorporados en 2004 (Chipre, Eslovenia, Eslovaquia, Estonia, Hungria, Letonia, Lituania, Malta, Polonia, República Checa), en 2007 (Bulgaria y Rumania) y en 2013 (Croacia). 
La gráfica 5 muestra el número de desplazamientos temporales por país de acogida en 2011. Asimismo, podemos apreciar que Alemania fue el Estado miembro "de destino" que mayor número de desplazamientos recibió: concretamente 311.361 , lo que supone un 25\% del total; Francia fue el segundo país que registró una mayor cantidad de movimientos laborales "en el empleo" con destino a su territorio: 161.954; a su vez, Bélgica, con un total de 125.107, fue el tercer país con más desplazamientos. Por lo que estos tres países suman más del 49\% del total de desplazamientos recibidos por los países del Espacio Económico Europeo. España, por su parte, recibió un total de 47.640 desplazamientos temporales de trabajadores dentro de sus fronteras, cifra inferior pero cercana en términos relativos a la de Austria, Italia y Suiza. En porcentaje, el conjunto de Estados miembros formado por Alemania, Francia, Bélgica, Holanda y Austria recibieron casi el 65\% de los desplazamientos acontecidos en el EEE en 2011.

A través del análisis estadístico del fenómeno se observa que más del $85 \%$ de los desplazamientos tuvo como "destino" alguno de los países miembros de la UE-15; asimismo, los países denominados UE-12 recibieron casi el 7\% del total de desplazamientos temporales. Y, por su parte, los países pertenecientes a la EFTA acogieron al 7.5\% de todos los movimientos laborales "en el empleo" acontecidos en 2011. Por su parte, se ha evidenciado que Francia y Alemania son países con un importante número de desplazamientos de trabajadores asalariados, tanto desde la perspectiva de envío, como desde la perspectiva de acogida. Por el contrario, Polonia sólo presenta una elevada cifra de desplazamientos desde la perspectiva de envío, siendo el país de la Unión Europea desde el que se efectúa un mayor número de movimientos laborales "en el empleo", en concreto casi un $20 \%$ del total.

\section{Aproximación jurídica. Marco legal aplicable}

A) Antecedentes jurídicos del desplazamiento de trabajadores en la UE

Como ya se ha anticipado en el epígrafe anterior, el fundamento jurídico que facilita la movilidad geográfica transnacional en el Espacio Económico Europeo por iniciativa del empleador no es la libre circulación de trabajadores, sino la libre prestación de servicios transnacional. Esta libertad otorga el derecho a las empresas a trasladarse de un Estado miembro a otro con la finalidad de prestar sus servicios de forma ocasional. Inexorablemente, este suceso suele ir acompañado del desplazamiento del personal propio de la empresa, y cuando esto sucede se 
produce un cambio temporal del lugar de trabajo de los trabajadores transitoriamente desplazados, quienes, "en principio", siguen sometidos al ordenamiento laboral de origen y no al del lugar donde temporalmente se presta el trabajo, según lo dispuesto en el Convenio de Roma de 1980 sobre la ley aplicable a las obligaciones contractuales. ${ }^{22}$ Este instrumento jurídico establece normas relativas a la ley aplicable a las obligaciones contractuales en la Unión Europea, y se aplica a los contratos de trabajo internacionales cuando los trabajadores de una empresa establecida en un Estado miembro ejercen sus actividades en uno o varios Estados miembros distintos al de su contratación originaria. De acuerdo con el mismo y, respecto con el derecho aplicable a los supuestos de movilidad intracomunitaria de trabajadores asalariados, este precepto legal señala que, siempre que la ley rectora del contrato de trabajo internacional no haya sido elegida por las partes, el contrato de trabajo se regirá:

Bien por la ley del país donde el trabajador realiza habitualmente su trabajo, aun cuando, con carácter temporal, haya sido enviado a otro país; bien por la ley del país donde se encuentre el establecimiento que haya contratado al trabajador; o bien por la ley del país con el que el contrato de trabajo presente vínculos más estrechos. ${ }^{23}$

En todos estos supuestos, la norma fija el derecho del "país de origen" como aquel que, a falta de elección por las partes, debe regir las obligaciones contractuales derivadas de un contrato de trabajo preexistente. Por tanto, la ley aplicable al desplazamiento se corresponde con la del lugar habitual de trabajo o establecimiento de la empresa, el cual prevalece sobre la ley aplicable en el lugar de prestación ocasional o transitorio. El carácter temporalmente limitado de estos desplazamientos determina tal circunstancia.

Ahora bien, el Convenio de Roma de 1980 admite la elección de la ley aplicable al contrato de trabajo (de origen o de destino) mediante acuerdo entre las partes, eso sí, siempre que la ley elegida sea más beneficiosa para el trabajador desplazado que la del lugar de ejecución habitual del trabajo. Sin embargo, lo habitual en las relaciones laborales conectadas con los supuestos de movilidad geográfica laboral "en el empleo" es la no elección por las partes de la legislación

\footnotetext{
22 El Convenio de Roma de 1980 es un Tratado de la Comunidad Económica Europea (CEE) que persigue la unificación de criterios sobre obligaciones contractuales en la Unión Europea. Se firmó en Roma el 19 de junio de 1980 y entró en vigor el $1^{\circ}$ de abril de 1991, disponible en: http://eur-lex.europa.eu/LexUriServ/LexUriServ.do?uri=celex:41998A0 126\%2802\%29:ES:HTML.

${ }^{23}$ Cfr. Artículo 6.2 del Convenio de Roma, del 19 de junio de 1980, sobre la ley aplicable a las obligaciones contractuales, y el artículo 8 del Reglamento (CE) 593/2008 (Roma I) del Parlamento Europeo y del Consejo que sustituye al Convenio de Roma transformándolo en un instrumento comunitario.
} 
aplicable al contrato o relación laboral, lo que supone "de hecho" y "de derecho" la aplicación del ordenamiento del "país de origen". De esta forma, los desplazamientos temporales de trabajadores podían resultar "desigualmente tratados y desprotegidos frente a las condiciones de trabajo más favorables del lugar del desplazamiento". ${ }^{24}$

En este contexto, y con la necesidad de elaborar un instrumento de derecho comunitario, hoy derecho de la Unión Europea, destinado a impedir la posible competencia desleal entre empresas y el deterioro de los derechos del trabajador desplazado, la Unión Europea, todavía compuesta por 15 Estados miembros, alcanzó un consenso político que redundó en la aprobación de la Directiva 96/71/ CE del Parlamento Europeo y del Consejo del 16 de diciembre de 1996 sobre el desplazamiento de trabajadores efectuado en el marco de una prestación de servicios. $^{25}$

Esta Directiva ${ }^{26}$ establece un marco legal para la provisión de servicios transnacionales por parte de las empresas dentro del ámbito geográfico de la Unión. Al mismo tiempo, y respecto a las condiciones de trabajo de los trabajadores desplazados, identifica un "núcleo mínimo" de normas laborales (jornada máxima de trabajo y periodos mínimos de descanso; salario mínimo; vacaciones anuales retribuidas; prevención de riesgos laborales e igualdad de trato, entre otras) que deben ser respetadas por las empresas desplazantes atendiendo a lo establecido en el país en cuyo territorio se realiza el trabajo. Estas reglas de protección imperativas deberán estar establecidas en el Estado miembro de acogida a través de disposiciones legales, reglamentarias y administrativas, y/o a través de convenios colectivos o laudos arbitrales declarados de aplicación general. Es decir, por acuerdos que, en principio, deben ser respetados por todas las empresas pertenecientes al sector o profesión en cuestión, correspondientes al ámbito de aplicación territorial de éstos. De este modo, las empresas que presten servicios transnacionales y, consecuentemente, desplacen a sus propios trabajadores deberán aplicar determinadas normas laborales de protección mínima del país de

\footnotetext{
${ }_{24}$ Casas BaAmonde, Maria Emilia. Los desplazamientos temporales de trabajadores en la Unión Europea..., op. cit., p. 28.

${ }^{25}$ La misma "fue aprobada con el único voto en contra de Reino Unido y la abstención de Portugal. El Gobierno británico, entonces conservador, se opuso a la Directiva porque era de la opinión de que dicha Directiva garantizaba demasiados derechos a los trabajadores y que ello perjudicaba la libre circulación de trabajadores, esto es, la importación y exportación de trabajadores a costes inferiores a los establecidos en el Estado miembro de destino". en Calvo Caravaca, Alfonso luis y Carrascosa González, Javier (dirs.). Derecho internacional privado, 11a. ed., Comares, Granada, 2010, p. 710.

${ }^{26}$ Una Directiva es un instrumento jurídico de derecho de la Unión Europea que obliga a los Estados miembros destinatarios en cuanto al resultado que deba conseguirse. Es decir, se trata de una norma reguladora flexible que obliga a las autoridades nacionales en un determinado aspecto, pero dejando a su elección la forma y los medios para conseguirlo, a través de la implementación o trasposición de lo acontecido en este tipo de norma a los respectivos ordenamientos internos nacionales.
} 
destino; salvaguardando, al mismo tiempo, las condiciones de origen, pues como expresa LANDA:

[...] la referida Directiva limita su ámbito de aplicación a las empresas que desplazan trabajadores cuyas condiciones salariales originarias, las de sus país de residencia, fueran menores que las remuneraciones que con carácter mínimo se reconocían en el país de desplazamiento, ya que en otro caso se aplicarían las condiciones del país de residencia. ${ }^{27}$

Tal como señala la doctrina, esta norma comunitaria de carácter social, pero con una finalidad predominantemente económica (asegurar la libre de prestación de servicios y evitar distorsiones en la competencia), ${ }^{28}$ resuelve el conflicto acerca del derecho aplicable a los trabajadores desplazados entre países del EEE, y lo hace de la siguiente forma: el contrato de trabajo del trabajador desplazado, tal como establecía el Convenio de Roma, seguirá sometido a la legislación laboral de origen y al mismo tiempo se verá configurado según lo dispuesto en la Directiva 96/71/ CE. La misma, de forma imperativa, exige la aplicación de un núcleo de normas laborales de protección mínima del país de destino. Con ello se trata de evitar que las empresas puedan llevar a cabo una actividad económica transnacional en condiciones de competitividad más favorables que otras, mediante el aprovechamiento de las diferencias en costes laborales y de protección social.

Cuadro 1. Condiciones de trabajo y empleo que deberán Ser Respetadas POR LOS EMPRESARIOS QUE DESPLACEN TRABAJADORES DE UN ESTADO MIEMBRO A OTRO SEGÚN LOS SUPUESTOS ESTABLECIDOS EN la DiRECTIVA 96/71/CE

1. Los Estados miembros velarán por que, cualquiera que sea la legislación aplicable a la relación laboral, las empresas mencionadas en el apartado 1 del artículo 1 garanticen a los trabajadores desplazados en su territorio las condiciones de trabajo y empleo relativas a las materias siguientes que, en el Estado miembro donde se efectúe el trabajo, estén establecidas:

- Por disposiciones legales, reglamentarias o administrativas, y/o

- Por convenios colectivos o laudos arbitrales declarados de aplicación general con arreglo al apartado 8 en la medida en que se refieran a las actividades contempladas en el Anexo:

\footnotetext{
27 Landa Zapirain, Juan Pablo. "En busca de una regulación equilibrada que permita conciliar el desarrollo del mercado único con el respeto exigible al ejercicio de los derechos sociales fundamentales: desde el diálogo social a la constitucionalización jurídica de la Unión Europea", en Revista del Ministerio de Trabajo e Inmigración, No. x, abril de 2010, estudios 87-107, p. 90.

${ }^{28}$ En este sentido, Rodriguez Piñero, Manuel. "El desplazamiento temporal de trabajadores...", op. cit., p. 82.
} 
a) Los periodos máximos de trabajo, así como periodos mínimos de descanso;

b) La duración mínima de las vacaciones anuales retribuidas;

c) Las cuantías de salario mínimo, incluidas las incrementadas por las horas extraordinarias; la presente letra no se aplicará a los regímenes complementarios de jubilación profesional;

d) Las condiciones de suministro de mano de obra, en particular por parte de agencias de trabajo interino;

e) La salud, la seguridad y la higiene en el trabajo;

f) Las medidas de protección aplicables a las condiciones de trabajo y de empleo de las mujeres embarazadas o que hayan dado a luz recientemente, así como de los niños y de los jóvenes;

g) La igualdad de trato entre hombres y mujeres y otras disposiciones en materia de no discriminación.

A los fines de la presente Directiva, la noción de cuantías de salario mínimo mencionada en la letra c) del párrafo primero se definirá mediante la legislación y/o el uso nacional del Estado miembro en cuyo territorio el trabajador se encuentre desplazado.

Fuente: artículo 3.1 de la Directiva 96/71/CE del Parlamento Europeo y del Consejo del 16 de diciembre de 1996 sobre el desplazamiento de trabajadores efectuado en el marco de una prestación de servicios.

En efecto, esta norma comunitaria obliga a las empresas establecidas en un país miembro a aplicar una serie de condiciones laborales y salariales mínimas del país de acogida cuando desplacen a sus trabajadores para llevar a cabo una prestación de servicios transnacional, pero no únicamente. Al mismo tiempo procura garantizar la libre circulación de trabajadores en la Unión Europea, los derechos laborales básicos de los trabajadores intracomunitarios desplazados y la libre concurrencia empresarial de prestación de servicios sin obstáculos o distorsiones en la competencia.

Conviene señalar, además, que el artículo 3.10 de la referida Directiva autoriza la ampliación de esta lista de materias, facultando a los Estados miembros a exigir a las empresas que desplacen a trabajadores, la aplicación de ciertos criterios legales de sus propios sistemas jurídicos, relativos a los términos y condiciones de empleo de los trabajadores desplazados, así como a las condiciones de trabajo y empleo fijadas en convenios colectivos o laudos arbitrales de "aplicación general" o de aplicación a todas las empresas pertenecientes al sector 
en cuestión y/o aquellos convenios colectivos celebrados por los interlocutores sociales más representativos y que sean aplicables al territorio nacional. ${ }^{29}$

Por el contrario, la Directiva fija determinadas “excepciones" que los Estados miembros pueden establecer a la aplicación inmediata de las normas laborales del país de acogida en determinados supuestos y aspectos, como por ejemplo cuando se trate de trabajos denominados de "escasa importancia" y/o cuando la duración máxima de los trabajos no supere los ocho días, salvo en el sector de la construcción.

En cualquier caso, esta norma comunitaria obliga a los Estados miembros a la vigilancia de las empresas desplazantes para que garanticen a los trabajadores desplazados condiciones de trabajo acordes con lo establecido en el Estado miembro de acogida. Pero no solamente eso, al mismo tiempo insta a los Estados miembros a asegurar una "igualdad de trato" entre las empresas nacionales y extranjeras que se hallen en una situación similar en lo referente a las materias enumeradas en su artículo 3.1 de la Directiva sobre desplazamiento de trabajadores.

Ahora bien, el cumplimiento de los objetivos de esta Directiva (impedir la competencia desleal entre empresas y el deterioro de los derechos laborales del trabajador desplazado), así como la efectiva implementación de la norma a los Estados miembros, ha estado cargada de dificultades. Primero por su efectiva interpretación, trasposición y aplicación por parte de los 28 Estados miembros que componen en la actualidad la Unión Europea. Segundo, por el gran contraste en términos jurídico-laborales entre los sistemas de relaciones laborales y de negociación colectiva en Europa; circunstancia, en parte, inobservada en el momento de aprobación de la Directiva, cuando la Unión Europea estaba todavía formada por quince Estados.

Por último, debido a la exégesis que el Tribunal de Justicia de la Unión Europea ha expresado en los recientes pronunciamientos conectados con el fenómeno. En ellos, como se expresará en el siguiente epígrafe, se ha dictaminado que la libre prestación de servicios de las empresas es un principio jurídico protegido por el derecho de la Unión Europea y, consecuentemente, ostenta una primacía sobre determinados derechos laborales colectivos ya atendidos en los países de origen. Asimismo, considera que la Directiva 96/71/CE, en relación con las condiciones laborales de los trabajadores desplazados del artículo 3.1 opera como máximos de protección en vez de como mínimos.

\footnotetext{
${ }^{29}$ Cfr. Artículo 3.8 y 3.10 de la Directiva 96/71/CE del Parlamento Europeo y del Consejo del 16 de diciembre de 1996 sobre el desplazamiento de trabajadores efectuado en el marco de una prestación de servicios. Disponible en: http:// eur-lex.europa.eu/LexUriServ/LexUriServ.do?uri=CELEX:31996L0071:ES:NOT.
} 


\section{B) La trasposición de la Directiva 96/71/CE y equilibrio normativo entre libre prestación de servicios y derechos laborales}

Tal como viene recogido por EUROFOUND, ${ }^{30}$ es posible identificar dos elecciones fundamentales por las que los Estados miembros del EEe pueden optar a la hora de implementar o trasponer la Directiva sobre el desplazamiento de trabajadores a su ordenamiento nacional; la primera elección es decidir si se aplica a los trabajadores desplazados a su territorio la "protección mínima" o la "protección completa/amplia" de su ordenamiento laboral. La segunda supone acordar si esa protección se aplicará a través de disposiciones legales o mediante la aplicación de los convenios colectivos.

Respecto de la primera elección, la distinción entre protección mínima o amplia es una cuestión crucial que afecta al alcance efectivo de la Directiva en el Estado miembro. La protección mínima no se extiende más allá de lo estrictamente enumerado en el artículo 3.1; recuérdese el denominado núcleo mínimo de disposiciones laborales. Mientras que la protección amplia, con las limitaciones que veremos posteriormente, puede suponer la aplicación de gran parte de la legislación laboral del país de acogida o de todo aquello recogido en el convenio colectivo afecto. En cualquier caso, ampliando lo estrictamente enumerado en el precepto recién señalado.

Respecto de la segunda elección que deben efectuar los Estados miembros para implementar la Directiva a su ordenamiento nacional, la norma comunitaria trata de garantizar la protección de los trabajadores desplazados mediante la aplicación, por parte de las empresas desplazantes, de la ley o los convenios colectivos del país de acogida. En la práctica así sucede hoy en día en buena parte de los Estados miembros de la Unión Europea, donde los convenios colectivos de aplicación a los trabajadores desplazados son de aplicación general. Sin embargo, en algunos países donde no existen convenios colectivos vinculantes, la protección real de los trabajadores desplazados se limita a las garantías mínimas legales. En otras situaciones sólo sustituyen las protecciones mínimas, pero no se aplican en su totalidad a los trabajadores desplazados.

Lo recién expuesto supone de facto, la inaplicación de algunas de las condiciones mínimas de trabajo en determinados casos y, sobre todo, han puesto de manifiesto las dificultades aplicativas de la norma sobre desplazamiento de tra-

\footnotetext{
${ }_{30}$ EUROFound es un órgano de la Unión Europea que contribuye a la planificación y el establecimiento de mejores condiciones de vida y de trabajo en Europa. Proporciona resultados, conocimientos y consejos, procedentes de estudios independientes y comparativos, a los gobiernos, las empresas, los sindicatos y a la Comisión Europea. Véase http://www.eurofound.europa.eu/.
} 
bajadores que, eventualmente, puede traducirse en una involución sociosalarial para los trabajadores desplazados con respecto a sus homólogos locales y/o en un elemento vertebrador de la competencia desleal entre empresas.

$\mathrm{Al}$ respecto, son paradigmáticos algunos pronunciamientos del Tribunal de Justicia de la Unión Europea, ${ }^{31}$ que, a través de recientes sentencias, ha adoptado y definido de forma estricta lo que se entiende por "disposiciones de orden público", haciendo excepcional la aplicación completa de las normas laborales nacionales a los trabajadores desplazados. Según este Tribunal, las empresas desplazantes están obligadas a respetar únicamente las materias enumeradas en el artículo 3.1 de la Directiva. La ampliación de esas materias, aunque destinadas a proteger a los trabajadores desplazados, podría suponer una restricción de la competitividad de las empresas desplazadas a otro mercado nacional y con ello una restricción a la libre prestación de servicios en la Unión Europea. Por ello, salvo que vengan justificadas por el orden público, el Estado miembro de acogida no puede imponer garantías adicionales a lo dispuesto en el citado artículo 3.1 de la Directiva. Esta circunstancia, tal como manifiestan diversos académicos, organizaciones sindicales, algunas instituciones europeas, el propio tJuE y otros organismos consultivos, hace que las materias denominadas como el "núcleo duro" del derecho del trabajo hayan pasado de ser los requisitos mínimos que las empresas están obligadas a respetar durante el desplazamiento de trabajadores, a ser los requisitos máximos. ${ }^{32}$

Pero no sólo las resoluciones judiciales citadas han situado en dos planos de regulación diferentes los derechos laborales colectivos (atendidos por las Constituciones nacionales de los Estados miembros), y las libertades económicas de las empresas en el mercado interior (garantizadas por el Tratado de Funcionamiento de la Unión Europea). La consecuencia inmediata de esta exégesis, argumentada jurídicamente, se concreta de esta forma: el ejercicio empresarial de una libertad fundamental, la libre prestación de servicios contenida en los artículos 56 y 62 del Tratado de Funcionamiento de la UE, es un principio jurídico protegido por

${ }^{31}$ Entre otros, SSTJCE del 18 de diciembre de 2007 (TJCE/2007/390, asunto C-341/05 Laval); del 3 de abril de 2008 (TJCE/2008/60, asunto C-346/06 Rüffert); del 19 de junio de 2008 (stJcE/2008/319, asunto c-319/06 Comisión vs. Luxemburgo).

32 Véase, entre otros, Merino Segovia, Amparo. "Las libertades económicas fundamentales de establecimiento y prestación de servicios: consecuencias e implicaciones de la reciente doctrina del tJcE en el sistema español de relaciones laborales", en Quaderno SindNova, No. 24: I percorsi della solidarietà. Lavoro, mercato e diritti nell'Unione Europea, 2009; Rodriguez-Piñero, Manuel. "El caso Rüffert ¿Una constitucionalización del dumping social?", en Relaciones Laborales, No. 15, 2008, pp. 213-244; EuRofound. Posted Workers in the European Union..., op. cit., p. 21; sentencia del tJCE del 19 de junio de 2008 (Asunto c-319/06 Comisión vs. Luxemburgo); Comité EConómico y Social EUROPEO. Dictamen de iniciativa sobre "La dimensión social del mercado interior", en Diario Oficial de la Unión Europea c44/90, Bruselas, 2011, p. 7. 
el derecho de la Unión Europea y, por lo tanto, detenta una primacía sobre determinados derechos laborales colectivos de los trabajadores. ${ }^{33}$

Esta interpretación jurídica ha suscitado un gran debate en el mundo universitario, social, académico, político e institucional, en torno a la ponderación entre derechos y libertades fundamentales en la Unión Europea, ${ }^{34} \mathrm{y}$ ha provocado, entre otras, la reacción del Parlamento Europeo que, a través de una resolución legislativa "sobre los retos para los convenios colectivos en la Unión Europea [2008/2085 (INI)]", ${ }^{35}$ aprobada en octubre de 2008, respondió a los pronunciamientos del TJUE, solicitando de forma expresa llevar a cabo medidas jurídicas orientadas a garantizar que los cambios necesarios en la legislación europea traten de proporcionar un equilibrio entre los derechos laborales de los trabajadores y la libre prestación de servicios, con la finalidad de contrarrestar los posibles efectos perjudiciales que desde el punto de vista social, económico y político podrían tener las sentencias recientes del TJUE. Estas medidas, como expresa el Parlamento Europeo, deben orientarse principalmente a la revisión de la Directiva 96/71/ce sobre desplazamiento de trabajadores y a la adopción de medidas en contra de las denominadas "empresas buzón". ${ }^{36}$

De esta forma, la resolución legislativa del Parlamento europeo, unida a diversos pronunciamientos académicos, sociales e institucionales en la Unión Europea, han incidido de forma significativa en la adopción de una iniciativa legislativa concreta a nivel europeo; el 21 de marzo de 2012 se publicó la propuesta de Directiva del Parlamento Europeo y del Consejo, relativa a la garantía de cumplimiento de la Directiva 96/71/CE sobre desplazamiento de trabajadores efectuado en el marco de una prestación de servicios y, la propuesta de Reglamento del Consejo sobre el ejercicio del derecho a adoptar medidas de conflicto

\footnotetext{
${ }_{33}$ Así lo expresan, entre otros, Baylos Grau, Antonio. "El espacio supranacional de ejercicio del derecho de huelga y la restricción legal de sus capacidades de acción", en Revista de Derecho Social, No. 41, enero-marzo de 2008, 123-143, p. 128, y LANDA ZAPIRAIn, JuAN PABLo. "En busca de una regulación equilibrada que permita conciliar el desarrollo del mercado único con el respeto exigible al ejercicio de los derechos sociales fundamentales...", op. cit., p. 91.

${ }^{34}$ En junio de 2009 más de un centenar de juristas y profesores de derecho del trabajo de toda Europa dirigieron una carta abierta a los jefes de Estado o de gobierno para expresar su gran inquietud ante el deterioro de los derechos sociales fundamentales y la repercusiones de las recientes sentencias dictadas por el tJuE sobre los derechos de los trabajadores y sus organizaciones. Expresaban, a su vez, su preocupación por el hecho de que las sentencias habian creado graves problemas para a la protección efectiva de los derechos de los trabajadores. Las mismas pueden verse en http://www.etui.org/en/Headline-issues/Viking-Laval-Rueffert-Luxembourg/2-Articles-in-academic-literatureon-the-judgements.

35 El texto completo que incluye el informe y la propuesta de resolución al Parlamento Europeo está disponible en: http://www.europarl.europa.eu/sides/getDoc.do?pubRef=-//EP//NONSGML+REPORT+A6-2008-0370+0+DOC+PDF+VO//ES.

${ }^{36}$ Tal como recoge esta Resolución del Parlamento Europeo en las peticiones de la Exposición de motivos, las "empresas buzón" son aquellas sociedades "que no se dedican a negocios verdaderos y significativos en el pais de origen, sino que son creadas, a veces incluso directamente por el principal contratista en el país de acogida, con el único propósito de ofrecer "servicios» en el pais de acogida para evitar la aplicación de las normas de ese país, sobre todo en lo que respecta a los salarios y las condiciones de trabajo".
} 
colectivo en el contexto de la libertad de establecimiento y la libre prestación de servicios, ${ }^{37}$ el denominado Reglamento Monti 11.

Ahora bien, esta propuesta no resuelve un aspecto clave del fenómeno, pues, de forma ambigua, supedita los intereses y derechos laborales de los trabajadores desplazados a los del mercado interior limitando determinados derechos colectivos de los trabajadores, tal como el derecho a la huelga. Circunstancia que provocó el rechazo de la propuesta por parte de la Comisión Europea. De este modo, la misma fue retirada el 11 de septiembre de 2012 sobre la base de la cláusula de flexibilidad relativa a la realización del mercado interior (artículo 352 del TFUE $)^{38}$ y ha aplazado indefinidamente la revisión de los aspectos normativos que a nivel europeo deben responder a uno de los elementos congénitos de la integración económica en el territorio de la Unión Europea.

\section{Consideraciones finales}

El desplazamiento de trabajadores asalariados, vinculado a la libertad económica de prestación de servicios transnacionales en la Unión Europea, es un componente clave para la consolidación del mercado interior. Sin la posibilidad de desplazar trabajadores, las empresas en Europa no efectuarían gran parte de las prestaciones de servicios transnacionales entre Estados miembros. Sin embargo, esta manifestación de movilidad laboral geográfica adolece de una incompleta y obsoleta regulación jurídica. En la actualidad, la misma no responde eficaz y proporcionadamente a los desafíos que le son inherentes. Como se ha visto, uno de los aspectos que mayores críticas y reflexiones despierta este fenómeno es el impacto que para los trabajadores afectados puede suponer su desplazamiento temporal a un Estado miembro donde la protección social y el salario sea menor. A su vez, la competencia leal entre empresas puede verse alterada como consecuencia de la concurrencia, para la prestación de un mismo servicio, de empresas

\footnotetext{
${ }^{37}$ Comisión EuropeA, Propuesta de Directiva del Parlamento Europeo y del Consejo, relativa a la garantía de cumplimiento de la Directiva 96/71/CE sobre desplazamiento de trabajadores efectuado en el marco de una prestación de servicios, com/2012/0131 final 2012/0061 (CoD), del 21 de marzo de 2012, disponible en: http://eur-lex.europa.eu/ LexUriServ/LexUriServ.do?uri=celex:52012PC0131:ES:NOT, y Propuesta de Reglamento del Consejo, sobre el ejercicio del derecho a adoptar medidas de conflicto colectivo en el contexto de la libertad de establecimiento y la libre prestación de servicios, Com/2012/0130 final 2012/0064 (CoD), del 21 de marzo de 2012, disponible en: http://eur-lex.europa.eu/ LexUriServ/LexUriServ.do?uri=CELEX:52012PC0130:ES:NOT.

${ }^{38}$ El artículo 352 del TFuE contiene la denominada cláusula de flexibilidad relativa a los ámbitos de competencia de la UE. La misma permite ajustar las competencias de la Unión a los objetivos asignados por los tratados cuando éstos no hayan previsto los poderes de acción necesarios para alcanzar dichos objetivos. Véase Comisión Europé. Síntesis de la legislación de la uE, glosario, "Competencias subsidiarias", disponible en: http://europa.eu/legislation_summaries/ glossary/subsidiary_powers_es.htm.
} 
procedentes de distintos países miembros. Lo que ocasionalmente puede traducirse en un factor de desigualdad socioeconómica y/o de inseguridad jurídica en vez de un elemento de cohesión, prueba de la efectiva integración europea.

Ineludiblemente, el proceso de integración económica en el territorio de la Unión Europea ha favorecido una cierta convergencia entre los Estados, sin embargo, en términos jurídico-laborales, la existencia de 28 ordenamientos laborales y la carencia de un derecho del trabajo armonizado provoca externalidades negativas tanto para los países y empresas implicadas como para los trabajadores temporalmente desplazados.

En este contexto es necesaria la adopción de un instrumento legal en el marco del derecho de la Unión Europea que reforme la Directiva 96/71/CE, con la finalidad de armonizar el control de su aplicación en los distintos Estados miembros y que aborde, asimismo, las dificultades hermenéuticas que la normativa actual presenta. Sobre todo a raíz de las sentencias del Tribunal de Justicia de la Unión Europea, las cuales han dado lugar a una interpretación restrictiva de la Directiva sobre desplazamiento de trabajadores, haciendo excepcional la ampliación de las "condiciones mínimas" de trabajo y empleo de las condiciones laborales aplicables a los desplazamientos, y que han suscitado dudas respecto de la ponderación entre libre prestación de servicios y derechos laborales fundamentales, como el derecho de huelga. Conviene recordar que este derecho se trata de un principio garantizado por la Carta de Derechos Fundamentales de la UE y, consecuentemente, no puede verse sometido por las libertades económicas cuando éstas vulneran las leyes y prácticas nacionales en el ámbito social.

En definitiva, el desplazamiento de trabajadores asalariados en la Unión Europea, vinculado a las libre prestación de servicios trasnacionales, es un fenómeno en desarrollo que debe ser objeto de una rigurosa restructuración legal, tanto a nivel europeo como a nivel estatal, de forma que se clarifiquen ciertos aspectos clave que aporten seguridad jurídica a los actores implicados y que, al mismo tiempo, fomenten una de las principales libertades económicas existentes en el territorio europeo. 